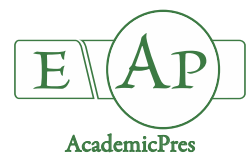

\title{
Physiological Effects of the Fungicide Azoxystrobin on Wheat Seedlings under Extreme Heat
}

\author{
Chiu-Yueh LAN ${ }^{1}$, Kuan-Hung LIN ${ }^{2}$, Wen-Dar HUANG ${ }^{1 *}$, \\ Chang-Chang $\mathrm{CHEN}^{3 * *}$ \\ ${ }^{1}$ National Taiwan University, Department of Agronomy, Daan, Taipei 101, \\ Taiwan;donutstream@gmail.com; wendar@ntu.edu.tw (*co-corresponding author) \\ ${ }^{2}$ Chinese Culture University, Department of Horticulture and Biotechnology, Shilin, Taipei 114, Taiwan; rlin@faculty.pccu.edu.tw \\ ${ }^{3}$ National Research Institute of Chinese Medicine, Ministry of Health and Welfare, Taipei, \\ Taiwan; chencc@nricm.edu.tw ${ }^{* *}$ correspondingauthor $)$
}

\begin{abstract}
Azoxystrobin (AZ) is not only a fungicide used for disease control, but also a protective chemical for crops against specific stresses. The physiological mechanism of the fungicide $\mathrm{AZ}$ in protecting against heat $\left(\mathrm{HT}, 46{ }^{\circ} \mathrm{C}\right)$ stress in wheat (Triticum aestivum L.) seedlings was investigated. 'Taichung SEL-2' variety seedlings were pretreated with $0.4,4,40,80$, and $120 \mathrm{mg} \mathrm{L}^{-1}$ of AZ for $4 \mathrm{~d}$. Next AZ-pretreated and untreated seedlings were subjected to HT for $1 \mathrm{~h}$ followed by $1000 \mu \mathrm{mol} \mathrm{m}^{-2} \mathrm{~s}^{-1}$ lighting for $20 \mathrm{~min}$. HT induced oxidant stress which resulted in a decrease in the reducing power, an increase in malondialdehyde, and enhanced enzyme activities of ascorbate peroxidase (APX) and catalase (CAT) in leaves of untreated seedlings. However, AZpretreated seedlings under HT displayed reductions in chlorophyll fluorescence, APX and CAT activities, and the 1,1diphenyl-2-picryl-hydrazyl scavenging capacity. Physiological damage caused by HT was aggravated by an increase in the AZ concentration. In addition, increased photosynthetic pigments were also observed in leaves of AZ-pretreated and HT-exposed seedlings. The results suggest that AZ does not provide a protective effect against $\mathrm{HT}$ stress.
\end{abstract}

Keywords: antioxidant activity; azoxystrobin; chlorophyll fluorescence; heat stress; wheat

\section{Introduction}

Under the influence of global warming, heat waves have impacted wheat production around the world with increasing frequency and intensity (Teixeira et al., 2013; Asseng et al., 2014). Heat is one of the main environmental factors influencing wheat yields and physiological senescence, such as inhibiting antioxidant enzyme activities and enhancing lipid peroxidation (Zhao et al., 2007). Maintaining wheat's physiological functions under sudden heat waves is an urgent issue, as well as preserving wheat yields and quality from acute and unexpected heat waves. In order to promote crop performances under adverse conditions, applying protective chemicals is one preventive strategy to protect against stresses (Gondim et al., 2012). Introduced in the 1990s, strobilurins are a group of chemicals used as systemic fungicides, and one of the most widely used strobilurin is azoxystrobin (AZ) (Giuliani et al., 2011). Strobilurins are also certified as chemical agents for promoting yields and delaying senescence in some crops, such as rice and wheat (Grossmann and Retzlaff, 1997; Wu and von Tiedemann, 2001). Therefore, strobilurins are also classified as plant bioregulators (Rademacher, 2004).

Previous studies reported that strobilurins stimulate nitrogen assimilation (Debona et al., 2016), mediate plant hormones, cause leaf aging delays, increase chlorophyll contents (Grossmann and Retzlaff, 1997), mitigate oxidative stress (Wu and von Tiedemann, 2001; Zhang et al., 2010), and improve plant water use efficiency and stabilize yields during droughts (Giuliani et al., 2011; Cantore et al., 2016). Furthermore, strobilurins also enhance the activity of nitrate reductase, a key enzyme involved in plant nitrogen assimilation, while raising nitrogen assimilation (Debona et al., 2016). Grossmann and Retzlaff (1997) demonstrated that kresoxim-methyl, one type of strobilurin with auxin-like activity, induced plant morphogenesis and differentiation, reduced the activity of aminocyclopropane-1-carboxylic acid synthase which is involved in the ethylene synthesis pathway, and increased 
684

chlorophyll (Chl) contents in leaves, suggesting that strobilurins might provide protective effects against senescence. Moreover, application of AZ increased the antioxidant enzyme activity with a reduction in free radicals in plants, and reduced protein contents and electrolyte leakage from leaves (Wu and von Tiedemann, 2001; Zhang et al., 2010).

Cantore et al. (2016) and Giuliani et al. (2011) indicated that $\mathrm{AZ}$ and other strobilurin fungicides reduced stomatal conductance and water evaporation, and promoted the water use efficiency (WUE) in tomatoes cultivated in an arid environment. The effects of $\mathrm{AZ}$ on the WUE of plants are related to an increase of endogenous abscisic acid and mediation of stomatal closure (Venancio $e t$ al., 2003). However, Nason et al. (2007) observed that the beneficial effects which strobilurins provided of alleviating the WUE and evapotranspiration of crops grown in waterdeficient environments were extremely limited, and this resulted in a reduction in the maximum quantum yield $\left(\mathrm{F}_{\mathrm{v}} / \mathrm{F}_{\mathrm{m}}\right)$. Debona et al. (2016) revealed that AZ mediated stomatal movements and inhibited the photosynthesis capacity, but did not influence $\mathrm{Chl}$ fluorescence (ChlF) or levels of photosynthetic pigments. The effects of strobilurins on stomata are complex and require further clarification. In addition, Swoboda and Pedersen (2009) illustrated that pyraclostrobin, a kind of strobilurin, did not promote the growth or yields of soybeans. Amaro et al. (2018) observed that AZ blocked electron transfer of the cytochrome- $b c_{l}$ complex in mitochondria and inhibited the respiration of plants, followed by a decrease in adenosine triphosphate and a reduction in the osmotic potential of guard cells, which was associated with the degree of stomatal opening. The main mechanism of $\mathrm{AZ}$ in reducing pathogen-induced oxidative stress from pathogen infections was to limit the expansion of the pathogen rather than increasing the antioxidant activity (Debona and Rodrigues, 2016).

Strobilurin-induced delay of senescence in plants is well described. Unfortunately, strobilurins might not be able to provide protective effects when a plant is under a water deficit or is infected with a pathogen. However, Pedersen (2016) found that AZ promoted endogenous cytokinins and phenolic components of creeping bentgrass for maintaining physiological functions under heat stress. Nevertheless, there is no study on whether strobilurins can also provide crops with protective effects during heat stress. In this study, the effects of AZ applications on the ChlF and antioxidant activities of wheat seedlings grown under high heat (HT) were evaluated.

\section{Materials and Methods}

\section{Plant and growth conditions}

Wheat (Triticum aestivum L.) cultivar 'Taichung SEL-2' (TCS2), one of the most widely grown wheat cultivars in Taiwan, was used in this study. The seeds were sterilized with $1 \%$ hydrogen peroxide for $5 \mathrm{~min}$, washed with distilled water, and germinated in Petri dishes on wetted filter paper at $25^{\circ} \mathrm{C}$ in the dark. After $24 \mathrm{~h}$ of incubation, uniformly germinated seeds were selected and cultivated in 150-ml beakers containing one-fifth-strength Hoagland nutrient solution (Hoagland and Arnon, 1950), and the solution was replaced every $2 \mathrm{~d}$. Hydroponically cultivated wheat seedlings were raised in growth chambers with fluorescent lamp lighting at 30 and $25^{\circ} \mathrm{C}$ at day and night, respectively, under a 12 -h photoperiod. The photosynthetic photon flux density (PPFD) was uniformly set to $300 \mu \mathrm{mol} \mathrm{m} \mathrm{m}^{-1}$.

\section{Experimental treatments}

Hydroponically grown seedlings that had reached stage Z1.0 (Zadoks et al., 1974) on day 4 were treated with the AZ fungicide (250 $\mathrm{g} \mathrm{AI} \mathrm{L}^{-1}$, Amistar, Syngenta Limited, Waterford, Ireland) at concentrations of $0.4,4,40,80$, and $120 \mathrm{mg} \mathrm{L}^{-1}$ for $4 \mathrm{~d}$. AZ was added to the nutrient solution according to the concentration of each $\mathrm{AZ}$ pretreatment. After $A Z$ treatment, these seedlings were placed in a high temperature of $46^{\circ} \mathrm{C}$ for $1 \mathrm{~h}$ in the dark as the HT condition. There were also a group of seedlings grown under HT without AZ pretreatment. Untreated seedlings were used as a control (CK). The experiment was independently performed three times for a randomized design of growth conditions.

\section{Measurements of chlorophyll fluorescence (ChlF)}

The fluorescence parameters in seedling leaves were determined after $1 \mathrm{~h}$ of HT in the dark. ChlF was measured in the middle portion of the first leaf of each seedling taken at ambient temperature with $\mathrm{Chl}$ fluorimeter imagingPAM (Walz, Effeltrich, Germany). Actinic light and saturating light intensities were set to 500 and $7200 \mu \mathrm{mol}$ $\mathrm{m}^{-2} \mathrm{~s}^{-1}$ of photosynthetically active radiation (PAR), respectively, and then the effective quantum yield of photosystem (PS)II under illumination $\left(\Phi_{\text {PSII }}\right)$ in leaves was determined after $1000 \mu \mathrm{mol} \mathrm{m} \mathrm{m}^{-2} \mathrm{~s}^{-1}\left(300 \mu \mathrm{mol} \mathrm{m} \mathrm{m}^{-2}\right.$ for $\mathrm{CK})$ lighting for $20 \mathrm{~min}$. The minimal $\left(\mathrm{F}_{0}\right)$ and maximal $\left(\mathrm{F}_{\mathrm{m}}\right) \mathrm{ChlF}$, maximum quantum yield of PSII $\left(\mathrm{F}_{\mathrm{v}} / \mathrm{F}_{\mathrm{m}}\right), \Phi_{\text {PSII, }}$ non-photochemical quenching (NPQ), the quantum yield of regulated energy dissipation of PSII (Y(NPQ)), the quantum yield of non-regulated energy dissipation of PSII $(\mathrm{Y}(\mathrm{NO})$ ), and the relative electron transfer rate (ETR) were measured and calculated according to previously described methods (Vankooten and Snel, 1990; Kramer et al., 2004).

\section{Measurement of ascorbate peroxidase $(A P X)$ and catalase (CAT) activity \\ APX activity was determined using the method of} Nakano and Asada (1981). Briefly, $0.06 \mathrm{~g}$ of the latest newly expanded leaf was placed in $2 \mathrm{~mL}$ sodium phosphate buffer $(50 \mathrm{mM}, \mathrm{pH} 6.8)$ in an ice bath for extraction and centrifuged at $4{ }^{\circ} \mathrm{C}$ and $12,000 \mathrm{~g}$ for $20 \mathrm{~min}$. The supernatant $(0.1 \mathrm{~mL})$ was collected, followed by the sequential addition of $2.7 \mathrm{~mL}$ of potassium phosphate buffer $(150 \mathrm{mM}, \quad \mathrm{pH}$ 7.0), $0.4 \mathrm{~mL}$ of ethylenediaminetetraacetic acid (EDTA, $0.75 \mathrm{mM}), 0.5 \mathrm{ml}$ of $\mathrm{H}_{2} \mathrm{O}_{2}(6 \mathrm{mM}), 0.5 \mathrm{~mL}$ of $\mathrm{H}_{2} \mathrm{O}$, and $0.5 \mathrm{~mL}$ of ascorbate $(1.5 \mathrm{mM})$ and then mixed well. The absorbance at $290 \mathrm{~nm}$ $\left(\mathrm{A}_{290}\right)$ of the sample solution was determined every $15 \mathrm{~s}$ for 1 min using a spectrophotometer (Hitachi U3010, Tokyo, Japan). The blank containing the same mixture with no enzyme extract was also measured. 
CAT activity was measured based on the method of Kato and Shimizu (1987). Briefly, $0.03 \mathrm{~g}$ of the latest newly expanded leaf was placed in $2 \mathrm{~mL}$ of sodium phosphate buffer $(50 \mathrm{mM}, \mathrm{pH} 6.8)$ in an ice bath for extraction and centrifuged at $4{ }^{\circ} \mathrm{C}$ and $12,000 \mathrm{~g}$ for $20 \mathrm{~min}$. The supernatant $(0.2 \mathrm{~mL})$ was collected, followed by adding 2.7 $\mathrm{mL}$ of sodium phosphate buffer $(100 \mathrm{mM}, \mathrm{pH} 7.0), 0.05$ $\mathrm{mL}$ of $\mathrm{H}_{2} \mathrm{O}$, and $0.05 \mathrm{ml}$ of $\mathrm{H}_{2} \mathrm{O}_{2}(1 \mathrm{M})$, and then mixing well. The absorbance of the sample solution at $240 \mathrm{~nm}$ $\left(\mathrm{A}_{240}\right)$ was determined every $15 \mathrm{~s}$ for $1 \mathrm{~min}$. The blank containing the same mixture with no enzyme extract was also measured.

Measurement of 1,1-diphenyl-2-picryl-hydrazyl (DPPH) scavenging capacity and the reducing power

The DPPH scavenging capacity was determined using the method of Shimada et al. (1992). Briefly, $160 \mu \mathrm{L}$ of a methanol extract of the sample combined with methanol or standard solution of butylated hydroxytoluene (BHT) was added to $40 \mu \mathrm{L}$ of a freshly prepared DPPH solution (1 $\mathrm{mM}$ ) to initiate the antioxidant-radical reaction at room temperature. The control was $160 \mu \mathrm{L}$ of sample extract, methanol, or BHT solution diluted to $200 \mu \mathrm{L}$. The absorbance of the reaction mixture was determined at 517 $\mathrm{nm}$ during a 30-min reaction time. The DPPH scavenging capacity was calculated using a curve of BHT standards. Results are expressed as $\mu \mathrm{g}$ BHT equivalent $\mathrm{g}^{-1}$ dry weight (DW).

The reducing power was determined using the method of Oyaizu (1986). Briefly, $0.3 \mathrm{~mL}$ of the methanol extract from a leaf was placed in $0.3 \mathrm{~mL}$ of sodium phosphate buffer $(0.2 \mathrm{M}, \mathrm{pH} 6.6)$ and $0.3 \mathrm{~mL}$ of $1 \% \mathrm{~K}_{3} \mathrm{Fe}(\mathrm{CN})_{6}$ in a water bath at $50{ }^{\circ} \mathrm{C}$ for $20 \mathrm{~min}$, immediately placed in $0.3 \mathrm{~mL}$ of $10 \%$ TCA in an ice bath, and then centrifuged at $9000 \mathrm{rpm}$ for $10 \mathrm{~min}$. The supernatant $(0.5 \mathrm{~mL})$ was mixed well with $0.5 \mathrm{~mL}$ distilled water and $0.1 \mathrm{~mL} \mathrm{FeCl}{ }_{3} \cdot \mathrm{H}_{2} \mathrm{O}(0.1 \%)$. The absorbance of the reaction mixture was determined at 700 $\mathrm{nm}$ during the 10-min reaction. The reducing power was calculated using a curve of BHT standards. Results are expressed as $\mathrm{mg}$ BHT equivalent $\mathrm{g}^{-1} \mathrm{DW}$.

\section{Determination of the malondialdehyde (MDA) content}

MDA was determined using a previously described method (Heath and Packer, 1968). Briefly, lyophilized sample powder $(0.03 \mathrm{~g})$ was mixed with $1 \mathrm{~mL}$ of $5 \% \mathrm{TCA}$, and then centrifuged at $10,000 \mathrm{rpm}$ and $20^{\circ} \mathrm{C}$ for $5 \mathrm{~min}$. The supernatant $(250 \mu \mathrm{L})$ was added to $1 \mathrm{~mL}$ of $0.5 \%$ thiobarbituric acid (TBA) which was made up with $20 \%$ TCA. The mixture was placed in a water bath at $95^{\circ} \mathrm{C}$ for $30 \mathrm{~min}$, and then immediately cooled in an ice bath. The reaction mixture was centrifuged at $3000 \mathrm{rpm}$ and $20^{\circ} \mathrm{C}$ for $10 \mathrm{~min}$, and the absorbance was determined at 532 and 600 $\mathrm{nm}$. The blank was the same reaction mixture with no sample extract.

\section{Determination of the photosynthetic pigment contents}

The photosynthetic pigment contents were determined using the method of Yang et al. (1998). Briefly, $0.01 \mathrm{~g}$ of lyophilized sample powder was extracted with $10 \mathrm{ml}$ of an $80 \%$ acetone solution, and then centrifuged at $4500 \mathrm{rpm}$ for $5 \mathrm{~min}$. The supernatant of the sample extract was tested to determine the absorbance of $\mathrm{Chl}$ a, $\mathrm{Chl} \mathrm{b}$, and carotenoids (Cars) in acetone at 663.6, 646.6, and $440.5 \mathrm{~nm}$, respectively.

\section{Statistical analyses}

All measurements were evaluated for significance using an analysis of variance (ANOVA) followed by a least significant difference (LSD) test at the $p<0.05$ level. All statistical analyses were conducted using $\mathrm{R}$ i386 3.5.1 software (https://cran.r-project.org/bin/windows).

\section{Results and Discussion}

Chlorophyll fluorescence (ChlF)

The response of ChlF can be used to evaluate the physiological condition of photosynthetic tissues in plants. Our preliminary data (data not shown) indicated that the light saturation point in leaves of seedlings was at $500 \mu \mathrm{mol}$ $\mathrm{m}^{-2} s^{-1} . \mathrm{F}_{\mathrm{v}} / \mathrm{F}_{\mathrm{m}}$ in leaves was determined after dark adaption with $\mathrm{HT}\left(\mathrm{CK}\right.$ at $\left.30^{\circ} \mathrm{C}\right)$ for $1 \mathrm{~h}$. With the exception of $\Phi_{\text {PSII, }}$ other ChlF parameters were determined at $500 \mu \mathrm{mol} \mathrm{m}^{-2} \mathrm{~s}^{-1}$. $\Phi_{\text {PSII }}$ was determined after $1000 \mu \mathrm{mol} \mathrm{m}^{-2} \mathrm{~s}^{-1}$ treatment (CK under $\left.300 \mu \mathrm{mol} \mathrm{m}^{-2} \mathrm{~s}^{-1}\right)$ for $20 \mathrm{~min}$.

$\mathrm{F}_{\mathrm{v}} / \mathrm{F}_{\mathrm{m}}$ and $\Phi_{\text {PSII }}$ are widely used to estimate the status under heat stress (Sun et al., 2006), and $\mathrm{F}_{\mathrm{v}} / \mathrm{F}_{\mathrm{m}}$ in CK seedling leaves was 0.80 . The difference in $\mathrm{F}_{\mathrm{v}} / \mathrm{F}_{\mathrm{m}}$ of leaves of untreated seedlings grown under HT and $\mathrm{CK}$ was insignificant. However, $\mathrm{F}_{\mathrm{v}} / \mathrm{F}_{\mathrm{m}}$ values of AZ-pretreated seedlings grown under $\mathrm{HT}$ were significant lower than that of $\mathrm{CK}$, and continued to decrease from 0.48 to 0.22 with an increase in the pretreated AZ concentration from 0.4 to 120 $\mathrm{mg} \mathrm{L}^{-1}$ (Fig. 1). A similar trend was observed in $\Phi_{\text {PSII }}$ in leaves of heated seedlings after exposure to light at 1000 $\mu \mathrm{mol} \mathrm{m} \mathrm{m}^{-1} \mathrm{~s}^{-1}$, and CK seedlings exposed to light at $300 \mu \mathrm{mol}$ $\mathrm{m}^{-2} \mathrm{~s}^{-1}$ for $20 \mathrm{~min}$ (Fig. 2). Meanwhile, an increase in $\mathrm{F}_{0}$ and a decrease in $F_{m}$ were observed in leaves of AZ-pretreated seedlings. Furthermore, a rise in the AZ concentration significantly influenced $\mathrm{F}_{0}$, but not $\mathrm{F}_{\mathrm{m}} . \mathrm{F}_{0}$ is a fluorescent signal when the PSII reaction center is fully open (Sun et al., 2006), and an increase in $F_{0}$ usually indicates that a plant is under stress (Song et al., 2013).

NPQ indicates the ability of plants to dissipate excess light energy, and is one of protective mechanisms against high light stress, while $\mathrm{Y}(\mathrm{NPQ})$ and $\mathrm{Y}(\mathrm{NO})$ are important indicators of photo-protection and photo-damage, respectively (Kramer et al., 2004). Lower NPQ levels were detected in leaves of seedlings pretreated with higher AZ concentrations and exposed to HT (Fig. 3), and the dynamics of $\mathrm{Y}(\mathrm{NPQ})$ also showed a similar pattern. On the other hand, $\mathrm{Y}(\mathrm{NO})$ in seedling leaves was enhanced with an increase in the $\mathrm{AZ}$ concentration, indicating that $\mathrm{AZ}$ pretreatment provided no protective effect for photosynthesis against $\mathrm{HT}$.

ChlF is an ideal tool for evaluating damage to a plant's photosynthetic tissues. In this study, decreases in $\mathrm{F}_{\mathrm{v}} / \mathrm{F}_{\mathrm{m}}$ and $\Phi_{\text {PSII }}$ in seedling leaves with an increase in the $\mathrm{AZ}$ concentration suggest that the damage level of the D1protein was more severe at higher pretreatment $\mathrm{AZ}$ concentrations. On the other hand, the increase in $\mathrm{F}_{0}$ also suggests that the light-harvesting complex had suffered irreversible damage, and/or the ability to transmit light 
686

energy from the antenna system to the PSII reaction center had degraded (Song et al., 2013). Meanwhile, the fall in NPQ and $\mathrm{Y}(\mathrm{NPQ})$ and increase in $\mathrm{Y}(\mathrm{NO})$ in seedling leaves also indicate loss of photo-protective ability and expansion of photo-damage (Kramer et al., 2004). These responses of ChlF parameters are consistent with results of previous studies (Nason et al., 2007; Debona et al., 2016) and suggest that an increase in the pretreated AZ concentration caused greater physiological damage to the photosystem in leaves.

These disadvantageous effects of strobilurin on ChlF might have resulted from blockage of the transmission of electrons between PSII and PSI because of the combination of strobilurin and Qi in the cytochrome $b f$ complex in chloroplasts (Nason et al., 2007). However, other studies reported that the foliar application of $\mathrm{AZ}$ might inhibit stomatal movement rather than ChlF, and would result in inefficient gas exchange (Debona et al., 2016; Amaro et al., 2018). In this study, AZ was added to the hydroponic solution rather than being applied to the foliage, and the impact of strobilurin on ChlF should be due to blockage of the transmission of electrons between PSII and PSI.
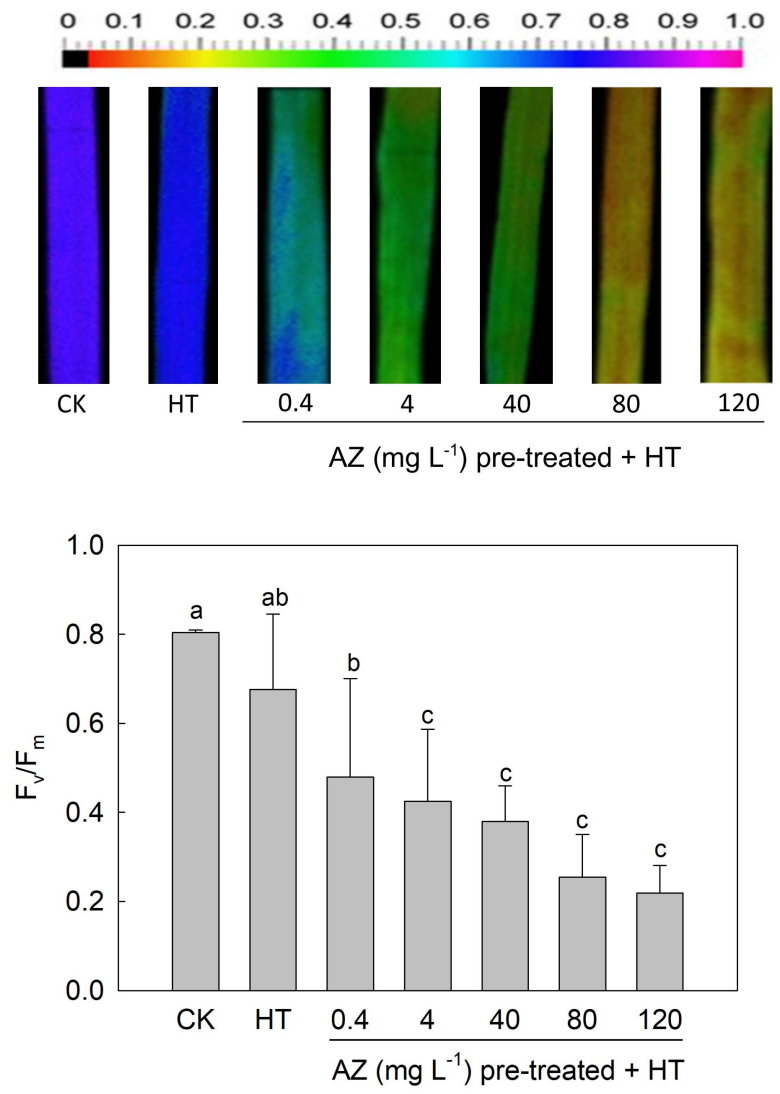

Fig. 1. Images of chlorophyll fluorescence in the maximum quantum yield of photosystem II $\left(\mathrm{F}_{\mathrm{v}} / \mathrm{F}_{\mathrm{m}}\right)$. The mean \pm standard deviation (error bar) of $\mathrm{F}_{\mathrm{v}} / \mathrm{F}_{\mathrm{m}}$ in leaves was determined in wheat seedlings treated with azoxystrobin (AZ) and grown under control (CK) or heated (HT) conditions. Values followed by different letters statistically significantly differ at $p<0.05$

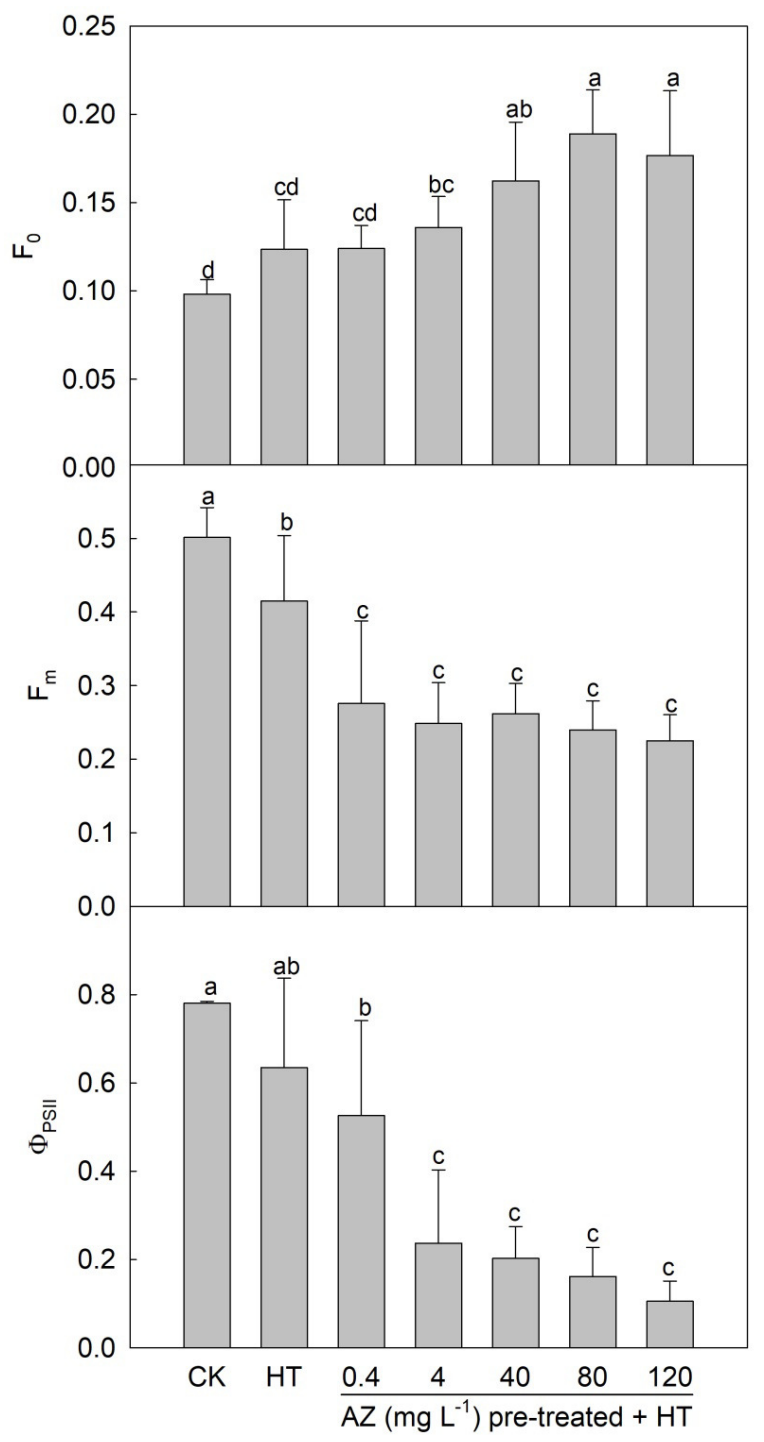

Fig. 2. The mean \pm standard deviation (error bar) of the minimal $\left(\mathrm{F}_{0}\right)$ and maximal $\left(\mathrm{F}_{\mathrm{m}}\right)$ chlorophyll fluorescence, and the effective quantum yield of photosystem II (PSII) under illumination $\left(\Phi_{\text {PSII }}\right)$ of leaves collected from wheat seedlings treated with azoxystrobin (AZ) and grown under the control (CK) or heated (HT) environment. Values followed by different letters statistically significantly differ at $p<0.05$

Activities of APX and CAT, DPPH scavenging capacity, and reducing power

APX activity in leaves of untreated seedlings grown under HT improved 86\% more than that of CK leaves (Fig. 4), indicating that HT induced APX activity. However, a continuous reduction in APX activity of AZ-pretreated and heated seedlings from 1.36 to $0.55 \mu \mathrm{mol}$ ascorbate $\mathrm{min}^{-1}$ $\mathrm{mg}^{-1}$ protein was observed with an increase in the AZ concentration up to $40 \mathrm{mg} \mathrm{L}^{-1}$. APX activities in leaves of seedlings subjected to pretreatment with $\mathrm{AZ}$ at $40 \mathrm{mg} \mathrm{L}^{-1}$ or higher were significantly lower than that of $\mathrm{CK}$ leaves. The dynamics of CAT activity in seedlings showed a different pattern from the results of APX. 


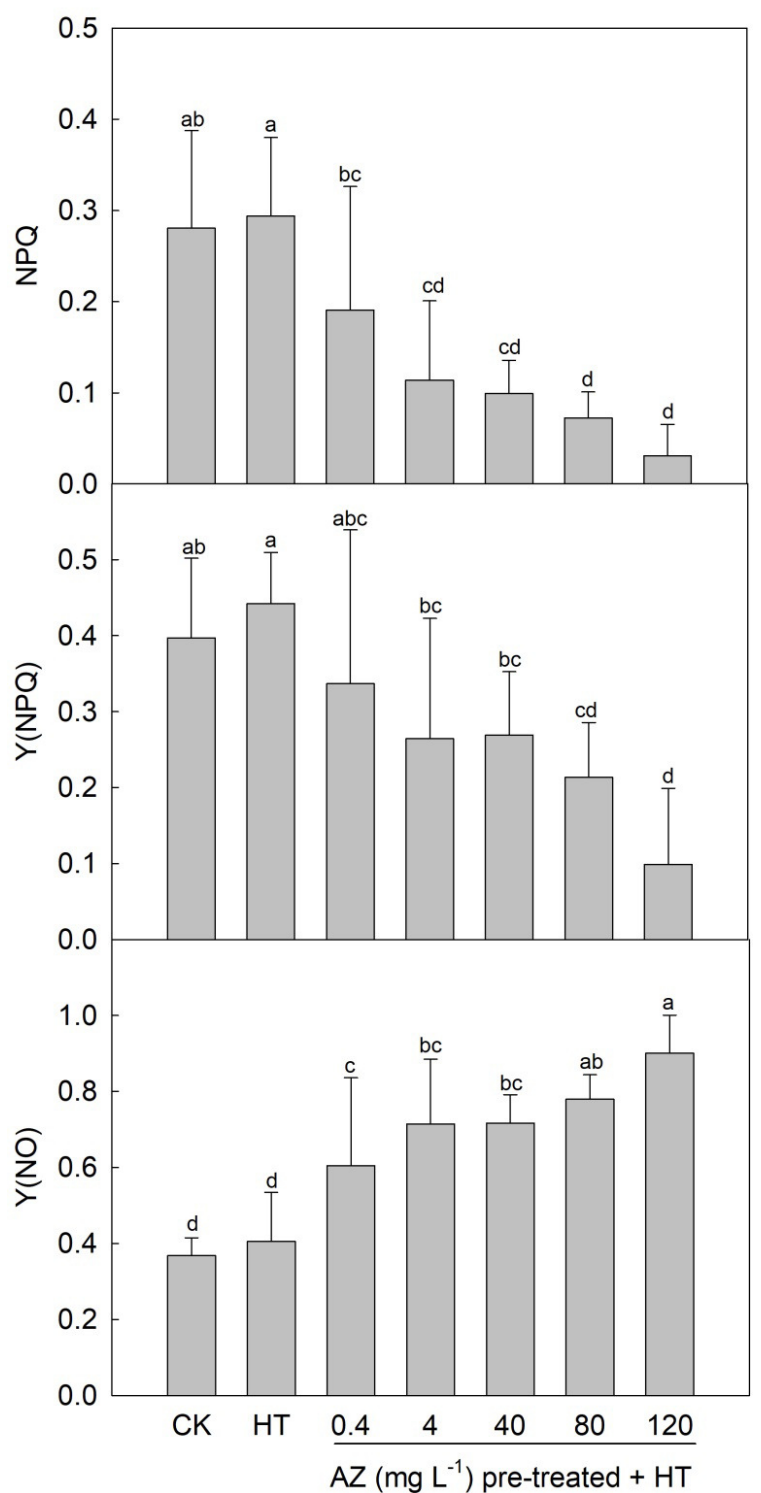

Fig. 3. The mean \pm standard deviation (error bar) of nonphotochemical quenching (NPQ), the quantum yield of regulated energy dissipation of photosystem II (PSII) (Y(NPQ)), and the quantum yield of non-regulated energy dissipation of PSII $(\mathrm{Y}(\mathrm{NO}))$ of leaves collected from wheat seedlings treated with azoxystrobin (AZ) and grown under the control (CK) or heated (HT) environment. Values followed by different letters statistically significantly differ at $p<0.05$

CAT activity of HT seedlings improved $24 \%$ more than that of $\mathrm{CK}$ seedlings $\left(0.43 \mu \mathrm{mol} \mathrm{H}_{2} \mathrm{O}_{2} \mathrm{~min}^{-1} \mathrm{mg}^{-1}\right.$ protein $)$, but did not increase as sharply as did APX. Furthermore, the sudden reduction in CAT activity from 0.50 to 0.35 $\mu \mathrm{mol} \mathrm{H}_{2} \mathrm{O}_{2} \mathrm{~min}^{-1} \mathrm{mg}^{-1}$ protein was determined in leaves of seedlings pretreated with AZ $40 \mathrm{mg} \mathrm{L}^{-1}$ and grown under
HT, implying that both APX and CAT activities in leaves of AZ-pretreated and heated seedlings were inhibited, and the critical concentration of AZ pretreatment was $40 \mathrm{mg} \mathrm{L}^{-1}$.

The difference in the DPPH scavenging capacity between CK (24.6 $\mu \mathrm{g}$ BHT equivalent $\left.\mathrm{g}^{-1} \mathrm{DW}\right)$ and HT leaves of seedlings (24.4 $\mathrm{\mu g}$ BHT equivalent $\left.\mathrm{g}^{-1} \mathrm{DW}\right)$ was insignificant, but a significant reduction in $\mathrm{DPPH}$ scavenging capacity from 24.4 to $14.6 \mu \mathrm{g} \mathrm{BHT}$ equivalent $\mathrm{g}^{-1}$ DW was observed in AZ-pretreated and heated seedlings with an increase in the AZ pretreatment concentration (Table 1). Nevertheless, the reducing power in leaves of HT seedlings (19.4 mg BHT equivalent $\mathrm{g}^{-1} \mathrm{DW}$ ) was significant lower than that of $\mathrm{CK}$ seedlings $(21.6 \mathrm{mg}$ BHT equivalent $\mathrm{g}^{-1} \mathrm{DW}$ ), but the difference in the reducing power in leaves of seedlings among the AZ-pretreated and heated groups was insignificant.

APX and CAT are involved in the antioxidant system to protect against stress-induced reactive oxygen species (ROS). Wu and von Tiedemann (2001) showed that AZ induced a delay in senescence which resulted from an increase in superoxide dismutase activity. Zhang et al. (2010) also suggested that AZ enhanced the activity of antioxidant enzymes, including CAT, and induced a delay in senescence. In our study, the activities of APX and CAT in seedling leaves were enhanced after being exposed to HT for $1 \mathrm{~h}$, but suppression of enzyme activities was observed in AZ-pretreated seedlings. Furthermore, AZ also reduced the DPPH radical scavenging capacity in leaves of seedlings after HT exposure, suggesting that AZ was unable to provide a protective effect against HT in seedlings, but in fact damaged the antioxidant system in seedling leaves. These results are consistent with a previous study by Debona and Rodrigues (2016) who observed that AZ suppressed stressinduced activities of APX and CAT in rice leaves. Moreover, Amaro et al. (2018) also reported that strobilurins, with the exception of $\mathrm{AZ}$, improved the activity of the antioxidative system.

Table 1. Effect of azoxystrobin (AZ) on the level of the DPPH radical scavenging capacity (expressed in $\mu \mathrm{g}$ BHT equivalent $\mathrm{g}^{-1}$ dry weight $(\mathrm{DW})$ ) and reducing power (expressed in $\mathrm{mg}$ BHT equivalent $\mathrm{g}^{-1} \mathrm{DW}$ ) in seedlings leaves collected from the control $(\mathrm{CK})$ or heated $(\mathrm{HT})$ condition

\begin{tabular}{ccc}
\hline Treatment & $\begin{array}{c}\text { DPPH radical scavenging } \\
\text { capacity }\end{array}$ & $\begin{array}{c}\text { Reducing } \\
\text { power }\end{array}$ \\
\hline $\mathrm{CK}$ & $24.6 \pm 0.8 \mathrm{a}$ & $21.6 \pm 0.2 \mathrm{a}$ \\
$\mathrm{HT}$ & $24.4 \pm 0.2 \mathrm{a}$ & $19.4 \pm 0.6 \mathrm{~b}$ \\
$\mathrm{AZ} 0.4 \mathrm{mg} \mathrm{L}^{-1}$ & $21.3 \pm 0.3 \mathrm{~b}$ & $19.9 \pm 0.2 \mathrm{~b}$ \\
$+\mathrm{HT}$ & $21.3 \pm 0.3 \mathrm{~b}$ & $19.0 \pm 0.6 \mathrm{~b}$ \\
$\mathrm{AZ} 4 \mathrm{mg} \mathrm{L}^{-1}+\mathrm{HT}$ \\
$\mathrm{AZ} 40 \mathrm{mg} \mathrm{L}^{-1}$ \\
$+\mathrm{HT}$ \\
$\begin{array}{c}\mathrm{AZ} 80 \mathrm{mg} \mathrm{L}^{-1} \\
+\mathrm{HT}\end{array}$ & $14.8 \pm 0.4 \mathrm{c}$ & $19.5 \pm 0.6 \mathrm{~b}$ \\
$\begin{array}{c}\mathrm{AZ} 120 \mathrm{mg} \mathrm{L}^{-1} \\
+\mathrm{HT}\end{array}$ & $15.7 \pm 0.1 \mathrm{c}$ & $19.4 \pm 1.1 \mathrm{~b}$ \\
\hline \begin{tabular}{l} 
Within columns, means followed by the same letter do not significantly differ \\
\hline
\end{tabular}
\end{tabular}
according to LSD test $(p<0.05)$. 
688

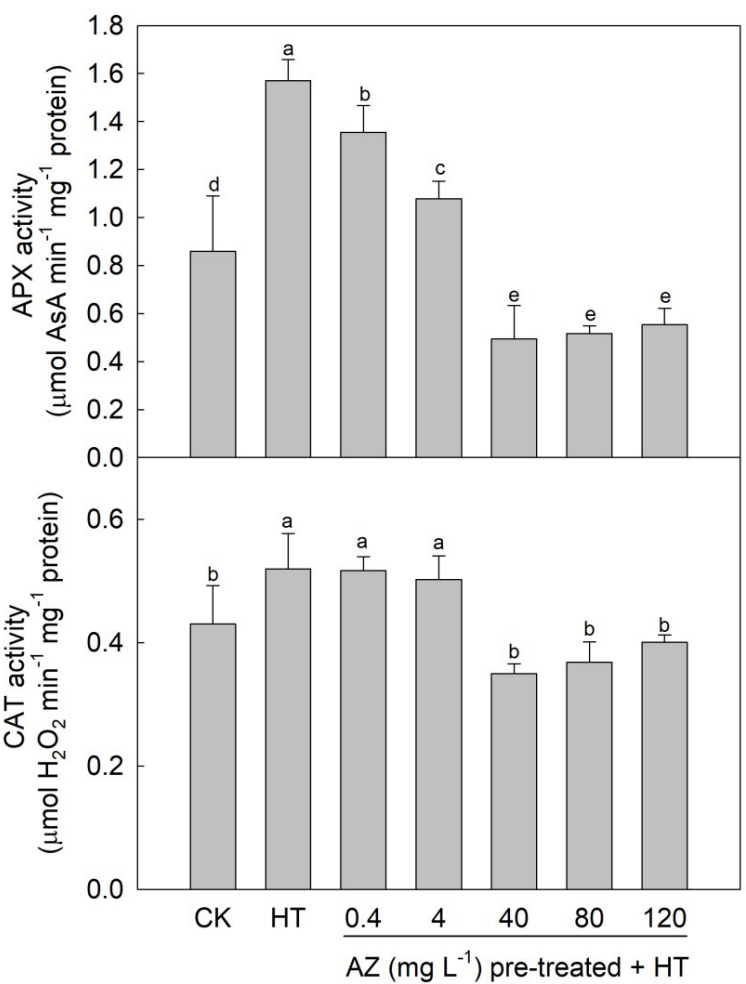

Fig. 4. The mean \pm standard deviation (error bar) of ascorbate peroxidase (APX) and catalase (CAT) activities of leaves collected from wheat seedlings treated with azoxystrobin (AZ) and grown under the control (CK) or heated (HT) environment. Values followed by different letters statistically significantly differ at $p<0.05$

\section{Malondialdehyde (MDA) content}

In plants, the content of MDA, a product of lipid peroxidation, reflects the status of heat-induced damage ( $\mathrm{Lu}$ et al., 2009; Bhardwaj and Ramandeep, 2017). Fig. 5 shows that the level of MDA in leaves of HT seedlings $(111 \mathrm{nmol}$ $\left.\mathrm{g}^{-1} \mathrm{DW}\right)$ was higher than that of CK seedlings $\left(100 \mathrm{nmol} \mathrm{g}^{-1}\right.$ DW). Meanwhile, a stable level (109 114 $\left.\mathrm{nmol} \mathrm{g}^{-1} \mathrm{DW}\right)$ of MDA in leaves of heated seedlings was observed among all AZ pretreatment concentrations. Zhang et al. (2010) observed that a reduction in MDA was accompanied by enhanced antioxidant enzyme activity. In our study, HT resulted in higher MDA levels in seedling leaves, but AZ neither enhanced nor suppressed the level of MDA in leaves of seedlings after exposure to HT. In addition, a similar trend was observed in the reducing power in leaves of seedlings after HT treatment. Debona and Rodrigues (2016) reported that glutathione, a chemical involved in the non-enzymatic system, inhibited oxidative stress. There might be another antioxidant mechanism, which was undermined in this study, in the AZ-treated seedlings against oxidant stress.

\section{Photosynthetic pigments}

Both Chl and Cars are involved in the light reaction of photosynthesis. Levels of total Chl (7.88 $\left.\mathrm{mg} \mathrm{g}^{-1} \mathrm{DW}\right)$, which is the sum of $\mathrm{Chl} \mathrm{a}$ and $\mathrm{Chl} \mathrm{b}$ contents, and Cars

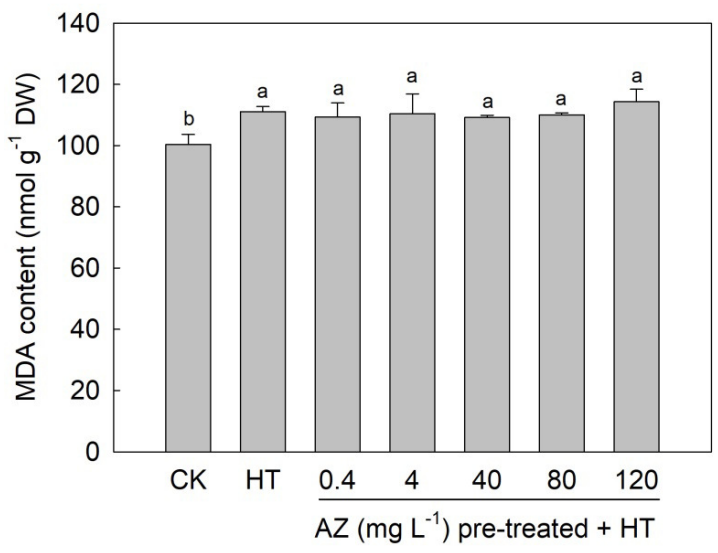

Fig. 5. The mean \pm standard deviation (error bar) of malondialdehyde (MDA) of leaves collected from wheat seedlings treated with azoxystrobin (AZ) and grown under the control $(\mathrm{CK})$ or heated (HT) environment. Values followed by different letters statistically significantly differ at $p<0.05$

Table 2. Effect of azoxystrobin (AZ) on the level of total chlorophyll (Chl; expressed in $\mathrm{mg} \mathrm{g}^{-1}$ dry weight $(\mathrm{DW})$ ), the $\mathrm{Chl} \mathrm{a/b}$ ratio, carotenoids (Car; expressed in $\mathrm{mg} \mathrm{g}^{-1} \mathrm{DW}$ ), and the Chl/Car ratio in seedling leaves collected from the control (CK) or heated (HT) condition

\begin{tabular}{|c|c|c|c|c|}
\hline Treatment & Total Chl & $\mathrm{Chla} / \mathrm{b}$ & Car & $\mathrm{Chl} / \mathrm{Car}$ \\
\hline $\mathrm{CK}$ & $7.76 \pm 0.19 b$ & $2.14 \pm 0.02 \mathrm{a}$ & $1.05 \pm 0.03 c$ & $7.39 \pm 0.33 a$ \\
\hline HT & $7.88 \pm 0.12 b$ & $2.13 \pm 0.01 \mathrm{a}$ & $1.07 \pm 0.03 \mathrm{c}$ & $7.35 \pm 0.11 \mathrm{a}$ \\
\hline $\begin{array}{c}\mathrm{AZ} 0.4 \mathrm{mg} \mathrm{L}^{-1} \\
+\mathrm{HT}\end{array}$ & $8.35 \pm 0.21 \mathrm{ab}$ & $2.14 \pm 0.02 \mathrm{a}$ & $1.11 \pm 0.06 \mathrm{bc}$ & $7.35 \pm 0.31 \mathrm{a}$ \\
\hline $\begin{array}{c}\mathrm{AZ} 4 \mathrm{mg} \mathrm{L}^{-1} \\
+\mathrm{HT}\end{array}$ & $8.83 \pm 0.53 \mathrm{a}$ & $2.14 \pm 0.01 \mathrm{a}$ & $1.14 \pm 0.05 \mathrm{ab}$ & $7.58 \pm 0.26 a$ \\
\hline $\begin{array}{c}\mathrm{AZ} 40 \mathrm{mg} \mathrm{L}^{-1} \\
+\mathrm{HT}\end{array}$ & $8.88 \pm 0.64 \mathrm{a}$ & $2.14 \pm 0.03 \mathrm{a}$ & $1.16 \pm 0.03 \mathrm{ab}$ & $7.65 \pm 0.44 \mathrm{a}$ \\
\hline $\begin{array}{c}\mathrm{AZ} 80 \mathrm{mg} \mathrm{L}^{-1} \\
+\mathrm{HT}\end{array}$ & $8.69 \pm 0.56 a$ & $2.13 \pm 0.01 \mathrm{a}$ & $1.17 \pm 0.06 \mathrm{ab}$ & $7.69 \pm 0.59 a$ \\
\hline $\begin{array}{c}\text { AZ } 120 \mathrm{mg} \mathrm{L}^{-1} \\
+\mathrm{HT}\end{array}$ & $8.78 \pm 0.14 \mathrm{a}$ & $2.13 \pm 0.02 \mathrm{a}$ & $1.23 \pm 0.01 \mathrm{a}$ & $7.15 \pm 0.08 \mathrm{a}$ \\
\hline
\end{tabular}

Within columns, means followed by the same letter do not significantly differ according to the LSD test $(p<0.05)$.

(1.07 $\left.\mathrm{mg} \mathrm{g}^{-1} \mathrm{DW}\right)$ in leaves of seedlings exposed to HT were consistent with those of $\mathrm{CK}$ seedlings. In addition, total $\mathrm{Chl}$ and Car contents in leaves of AZ-pretreated and heated seedlings exhibited a significant upward trend from 7.88 to $8.78 \mathrm{mg} \mathrm{g}^{-1} \mathrm{DW}$ and from 1.07 to $1.23 \mathrm{mg} \mathrm{g}^{-1} \mathrm{DW}$, respectively, with an increase in the $\mathrm{AZ}$ concentration applied (Table 2). However, differences in $\mathrm{Chl} \mathrm{a/b}$ ratios in leaves were insignificant among all experimental treatments.

Biotic and/or abiotic stresses usually lead to reductions in the contents of photosynthetic pigments (Ashraf and Harris, 2013; Chen et al., 2016). The lower Chl content in leaves might result from an imbalance between the biosynthetic and degradative pathways of Chl (Chen et al., 2015), but levels of photosynthetic pigments in leaves of HT seedlings were consistent with those of CK seedlings. Short-term exposure to HT probably did not effectively 
induce sharp reductions in pigment levels in leaves. On the other hand, AZ increased the accumulation of photosynthetic pigments in seedling leaves. A similar result was also presented in previous studies (Grossmann and Retzlaff, 1997; Wu and von Tiedemann, 2001), and the phenomena, such as a reduction in Chl degradation or a delay in leaf yellowing, is called a 'greening effect'. Our results showed that even though $\mathrm{AZ}$ induced a greening effect, it was obviously unable to protect against oxidant stress which was also caused by AZ. Song et al. (2013) reported that an enhanced $\mathrm{Chl} / \mathrm{Car}$ ratio could mitigate heat-induced oxidative stress. In our study, a stable ratio of $\mathrm{Chl} / \mathrm{Car}$ was observed in AZ-treated seedling leaves, and this might be another reason that $\mathrm{AZ}$ was unable to provide a protective effect against heat stress in wheat seedlings.

Strobilurin is one of the most important fungicides for plant disease control. In addition, strobilurin is also considered a chemical to improve crop physiology. The effect of strobilurins on wheat grown under a wellcontrolled environment without stress and applied during the later growth stages induced a delay in senescence and promoted grain yields (Wu and von Tiedemann, 2001; Zhang et al., 2010). Nevertheless, each strobilurin produced a dynamic effect on the plant's physiology and growth (Amaro et al., 2018), and the responses of crops to strobilurin are dramatically diverse at different growth stages (Zhang et al., 2010), and some specific physiological effects are only fully presented with sufficient $\mathrm{N}$ fertilizer (Ishikawa et al., 2012). A previous study reported that strobilurins alleviated paraquat-induced stress ( Wu and von Tiedemann, 2001), but reduced photosynthesis during a drought (Nason et al., 2007). The heat-induced oxidant stress decreased the Chl content and CAT activity, increased the MDA content, and ultimately reduced wheat yields (Zhao et al., 2007). In our study, the effect of AZ on the wheat seedlings exposed to sudden HT was also observed. Further studies on the protective effect of strobilurins in crops are needed.

\section{Conclusions}

This study explored the physiological mechanism of AZ in wheat seedlings exposed to sudden HT. AZ treatment displayed an ability to increase the contents of photosynthetic pigments in seedling leaves of wheat, but impacted ChlF, APX and CAT activities. There were no trends observed in the responses of the reducing power or MDA contents in leaves to AZ concentrations. Therefore, AZ provided limited support for the physiological functioning of wheat seedlings under HT stress.

\section{Conflicts of interest}

The authors declare that there are no conflicts of interest related to this article.

\section{References}

Amaro ACE, Ramos ARP, Macedo AC, Ono EO, Rodrigues JD (2018). Effects of the fungicides azoxystrobin, pyraclostrobin and boscalid on the physiology of Japanese cucumber. Scientia Horticulturae 228:66-75.
Ashraf M, Harris P (2013). Photosynthesis under stressful environments: an overview. Photosynthetica 51(2):163-190.

AssengS, Ewert F, Martre P, Rötter RP, Lobell DB, Cammarano D, ... Zhu Y (2014). Rising temperatures reduce global wheat production. Nature Climate Change 5(2):143.

Bhardwaj RD, Ramandeep K (2017). Protective role of pre-treatment with different phenolic acids in wheat seedlings against heat stress induced oxidative damage. Indian Journal of Agricultural Biochemistry 30(2):147-155.

Cantore V, Lechkar O, Karabulut E, Sellami MH, Albrizio R, Boari F, ... Todorovic M (2016). Combined effect of deficit irrigation and strobilurin application on yield, fruit quality and water use efficiency of "cherry" tomato (Solanum lycopersicum L.). Agricultural Water Management 167:53-61.

Chen YE, Cui JM, Su YQ, Yuan S, Yuan M, Zhang HY (2015). Influence of stripe rust infection on the photosynthetic characteristics and antioxidant system of susceptible and resistant wheat cultivars at the adult plant stage. Frontiers in Plant Science 6:779.

Chen YE, Liu WJ, Su YQ, Cui JM, ZhangZZW, Yuan M,... Yuan S(2016). Different response of photosystem II to short and long-term drought stress in Arabidopsis thaliana. Physiologia Plantarum 158(2):225-235.

Debona D, Nascimento KJT, Gomes JGO, Aucique-Perez CE, Rodrigues FA (2016). Physiological changes promoted by a strobilurin fungicide in the rice-Bipolaris oryzae interaction. Pesticide Biochemistry and Physiology 130:8-16.

Debona D, Rodrigues FA (2016). A strobilurin fungicide relieves Bipolaris oryzae-induced oxidative stress in rice. Journal of Phytopathology 164(9):571-581.

Giuliani MM, Nardella E, Gatta G, Caro AD, Quitadamo M (2011). Processing tomato cultivated under water deficit conditions: the effect of azoxystrobin. Acta Horticulturae 914:287-294.

Gondim FA, Gomes-Filho E, Costa JH, Alencar NLM, Prisco JT (2012). Catalase plays a key role in salt stress acclimation induced by hydrogen peroxide pretreatment in maize. Plant PhysiologyBiochemistry 56:62-71.

Grossmann K, Retzlaff G (1997). Bioregulatory effects of the fungicidal strobilurin kresoxim-methyl in wheat (Triticum aestivum). Pesticide Science 50(1):11-20.

Heath RL, Packer L (1968). Photoperoxidation in isolated chloroplasts: I. Kinetics and stoichiometry of fatty acid peroxidation. Archives of Biochemistry and Biophysics 125(1):189-198.

Hoagland DR, Arnon DI (1950). The water-culture for growing plants without soil. California Agricultural Experiment Station pp 347.

Ishikawa S, Hare MC, Kettlewell PS (2012). Effects of strobilurin fungicide programmes and fertilizer nitrogen rates on winter wheat: leaf area, dry matter yield and nitrogen yield. The Journal of Agricultural Science 150(4):427-441.

Kato M, Shimizu S (1987). Chlorophyll metabolism in higher plants. VII. Chlorophyll degradation in senescing tobacco leaves; phenolicdependent peroxidative degradation. Canadian Journal of Botany 65(4):729-735.

Kramer DM, Johnson G, Kiirats O, Edwards GE (2004). New fluorescence parameters for the determination of QA redox state and excitation energy fluxes. Photosynthesis Research 79(2):209. 
690

Lu J,ZhangR, ZongX, WangS, He G (2009).Effect of salicylic acid on heat resistance of rice seedling under heat stress. Chinese Journal of EcoAgriculture 17(6):1168-1171.

Nakano Y, Asada K (1981). Hydrogen peroxide is scavenged by ascorbatespecific peroxidase in spinach chloroplasts. Plant and Cell Physiology 22(5):867-880.

Nason MA, Bartlett D, Farrar J (2007). Strobilurin fungicides induce changes in photosynthetic gas exchange that do not improve water use efficiency of plants grown under conditions of water stress. Pest ManagementScience 63(12):1191-1200.

Oyaizu M (1986). Studies on products of browning reaction. Antioxidative activities of products of browning reaction prepared from glucosamine. Japanese Journal of Nutrition 44(6):307-315.

Pedersen MA (2016). Strobilurin fungicide secondary plant stress alleviation effects. $\mathrm{PhD}$ Thesis, University of Nebraska.

Rademacher W (2004). Recent situation and trends in global plant bioregulator utilization. Regulation of Plant Growth and Development 39(1):142-151.

Shimada K, Fujikawa K, Yahara K, Nakamura T (1992). Antioxidative properties of xanthan on the autoxidation of soybean oil in cyclodextrin emulsion. Journal of Agricultural and Food Chemistry 40(6):945-948.

Song L, Yue L, Zhao H, Hou M (2013). Protection effect of nitric oxide on photosynthesis in rice under heat stress. Acta Physiologiae Plantarum 35(12):3323-3333.

Sun Y, Xu W, Fan A (2006). Effects of salicylic acid on chlorophyll fluorescence and xanthophyll cycle in cucumber leaves under high temperature and strong light. The Journal of Applied Ecology 17(3):399-402.
Swoboda C, Pedersen P (2009). Effect of fungicide on soybean growth and yield. Agronomy Journal 101(2):352-356.

Teixeira EI, Fischer G, Van Velthuizen H, Walter C, Ewert F (2013). Global hot-spots of heat stress on agricultural crops due to climate change. Agricultural and Forest Meteorology 170:206-215.

Vankooten O, Snel JFH (1990). The use of chlorophyll fluorescence nomenclature in plant stress physiology. Photosynthesis Research 25(3):147-150.

Venancio WS, Rodrigues MaT, Begliomini E, De Souza NL (2003). Physiological effects of strobilurin fungicides on plants. Publicatio UEPG: Ciências Exatas e da Terra, Agrárias e Engenharias 9(3):59-68.

Wu Y,von Tiedemann AV (2001). Physiological effects of azoxystrobin and epoxiconazole on senescence and the oxidative status of wheat. Pesticide Biochemistry and Physiology 71(1):1-10.

Yang CM, Chang KW, Yin MH, Huang HM (1998). Methods for the determination of the chlorophylls and their derivatives. Taiwania 43(2):116-122.

Zadoks JC, Chang TT, Konzak CF (1974). A decimal code for the growth stages of cereals. Weed Research 14(6):415-421.

Zhang YJ, Zhou MG, Wang HC, Zhang X, Chen CJ (2010). Effects of fungicides JS399-19, azoxystrobin, tebuconazloe, and carbendazim on the physiological and biochemical indices and grain yield of winter wheat [electronic resource]. Pesticide Biochemistry and Physiology 98(2):151157.

Zhao H, Dai T, Jing Q, Jiang D, Cao W (2007). Leaf senescence and grain filling affected by post-anthesis high temperatures in two different wheat cultivars. Plant Growth Regulation 51(2):149-158. 